\title{
Parametric Study of Water Jet Pump Performance
}

\author{
Amr Hamza Hassan \\ High Dam Power Station., \\ Hydro Plant Generation Company, \\ Aswan, Egypt \\ amrhamza1980@gmail.com
}

\author{
Mohamed Shaban Eissa \\ Mechanical Power Eng. Dept., \\ Faculty of Energy Engineering \\ Aswan University \\ Aswan, Egypt \\ mshaban68@yahoo.com
}

\author{
Walid aniss Aissa* \\ Mechanical Power Eng. Dept., \\ Faculty of Energy Engineering \\ Aswan University \\ Aswan, Egypt \\ waessa@energy.aswu.edu.eg
}

\begin{abstract}
- this paper presents experimental and Computational Fluid Dynamic (CFD) analyses of a water jet pump. The effect of modifying the area ratio has been studied experimentally and numerically. A test rig has been planned to study the jet pump several parts using different dimensions and forms, to give more than one area ratio. The style of Computational Fluid Dynamic provides an origin for quantifying the consequences of operating circumstances on the pump performance. During this article, the measurements are conducted for four motivating pressures 1, 1.5, 2, and 2.5 bar. Also, three area ratio values are used; namely $0.19,0.29$ and 0.41 . The results illustrate and discuss velocity and pressure profiles. The worth of area ratio, which provides the highest efficiency was found to be 0.19. The Computational Fluid Dynamic results were found to agree well with actual values obtained from the experimental results.
\end{abstract}

Keywords— jet pump; experimental; CFD simulation; area ratio

\section{INTRODUCTION}

The jet pump is a device that utilizes the momentum transfer action from a high velocity jet fluid to pump another fluid, either equivalent or different from that of the jet. There are two sorts of jet pumps supporting different primary and secondary fluids input arrangements. The initial type is the central jet pump, which stratifying the first fluid to the inner nozzle and connecting the annular periphery-surrounding nozzle with the secondary fluid. The other is the annular jet pump, during which the suction fluid passes through the inner nozzle and therefore the primary fluid, is connected with the annular nozzle on the periphery of the suction tube. Gosline and O'Brien first suggested the theory of the jet pump [1], who established the governing equations to represent the processes in jet pumps. This theory was later improved to include the friction losses by investigators like Cunningham and River [2] and Vogel [3]. Mueller [4] carried out an experimental study on a water jet pump to obtain the optimum dimensions of the jet pump. Reddy and Kar [5], Sanger [6], Grupping et al. [7], and Hatziavramidis [8] carried theoretical and experimental studies on a water jet pump and suggested expressions for all energy losses in the various parts of the pump. Aissa, Eissa, and Mohamed [9] studied experimentally and theoretically the effect of changing some design parameters on the performance of a jet pump when handling water. Area ratio $R\left(=A_{n} / A_{t h}\right)$ is an essential factor that affects the pump efficiency, flow capacity, cavitation and pressure characteristics; $N$ and $M$ respectively. Pump area-ratio; $R$, can affect optimum throat length. Large $R$ pumps operate with high flow ratios and throat lengths of $L_{t h} / D_{t h}=8$. For pumps with small $R$ values, throat lengths of four diameters sufficed [10]. The current paper assumes that the ratio $R$ to be equal to $0.19,0.29$, and 0.41 , these corresponding to throat diameter of $16 \mathrm{~mm}, 13 \mathrm{~mm}$, and $11 \mathrm{~mm}$ with one nozzle diameter of $7 \mathrm{~mm}$. The values of the nozzle and throat diameters are shown in figures 1 , and 2 with the details are in table 1. CFD simulation may be a lower cost, reliable, and straightforward method than experimentation; it allows numerous tests requiring a smaller work area, less time, and personnel that create a superior simulation technique. This contemporary technique also provides the likelihood of performing modifications within the design with less expense and time, by quickly analyzing the flow field or physical details of flow improving and optimizing the planning. During this current article, the effect of primary pressure and area ratio on performance is studied experimentally and numerically. The test rig is described below. The Experimental results are compared with theoretical results Comparison indicated good agreement between experimental and theoretical results.

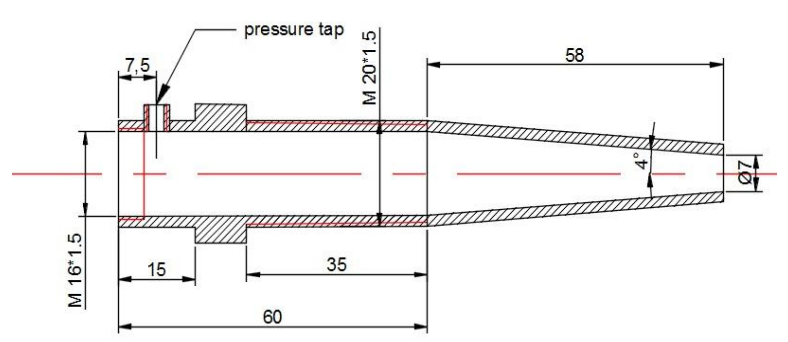

Fig. 1. 2-D Drawing of a driving nozzle 


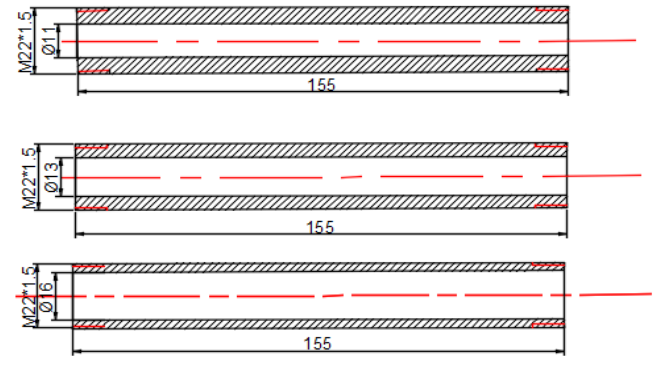

Fig. 2. 2D Drawing of the throat with different diameters

Table 1 Data of the area ratio

\begin{tabular}{|l|l|l|l|l|}
\hline EXP & $D_{t h}(\mathrm{~mm})$ & $L_{t h}(\mathrm{~mm})$ & $D_{n}$ & $R=\left(A_{n} / A_{t h}\right)$ \\
\hline $\mathbf{1}$ & 11 & 155 & 7 & 0.41 \\
\hline $\mathbf{2}$ & 13 & 155 & 7 & 0.29 \\
\hline $\mathbf{3}$ & 16 & 155 & 7 & 0.19 \\
\hline
\end{tabular}

\section{TEST RIG DESCRIPTION}

A graphic description of the experimental setup is schematically shown in figure 3. The experimental test rig consists of a $120 l$ sump tank (1) for the water system, centrifugal pump (2), water Jet pump (3). A suction valve (4), and a control valve (5), a bypass valve (6), discharge valve (7). The test rig is a closed-loop system where Tap water is pumped from the water tank to the jet pump. A bypass valve (6) is employed to regulate the inlet flow to the jet pump. The pump head and flow rates are $52 \mathrm{~m}$ and $70 \mathrm{l} / \mathrm{min}$, respectively. The jet pump on the way to the suction chamber lifts water from the suction tank (1) to the mixing chamber. Then, the water passes through the diffuser towards the tank.

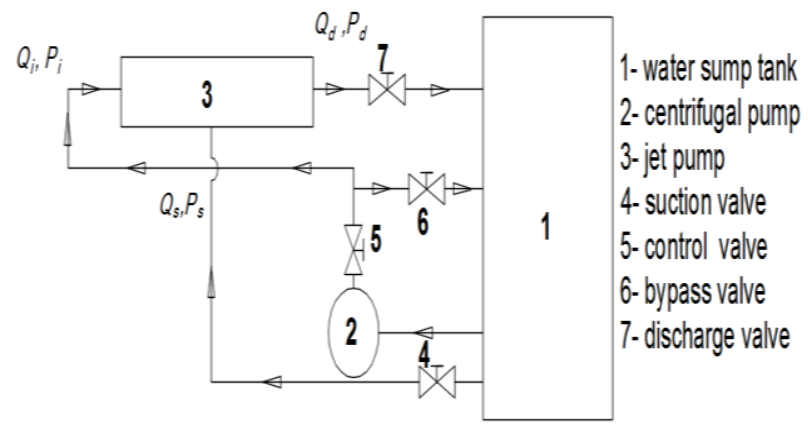

Fig. 3. Experimental test rig

Many parameters have been used to evaluate or compare the performance of jet pumps. In this work, three of them are used to describe and compare the performance of these jet pumps:

Mass flow ratio: $\quad M=Q_{s} / Q_{i}$

Pressure ratio: $\quad N=\left(H_{d}-H_{s}\right) /\left(H_{i}-H_{d}\right)$ where

$$
\begin{aligned}
& H_{i}=P_{i} / \gamma+V_{i}^{2} / 2 g+Z_{i} \\
& H_{d}=P_{d} / \gamma+V_{d}^{2} / 2 g+Z_{d} \\
& H_{s}=P_{s} / \gamma+V_{s}^{2} / 2 g+Z_{s}
\end{aligned}
$$

Efficiency: $\quad \eta=M * N * 100$

\section{TESTS, RESULTS AND DISCUSSION}

\section{A. Effect of Area Ratio and Driving Pressure on the Maximum Efficiency}

The effect of area ratio and, therefore, the driving pressure on the maximum efficiency is shown in figure 4 . The maximum efficiency is usually obtained at a worth of $(R=0.19)$. The maximum efficiency of a worth 16.5 percent is obtained at a worth of 2 bar driving pressure.

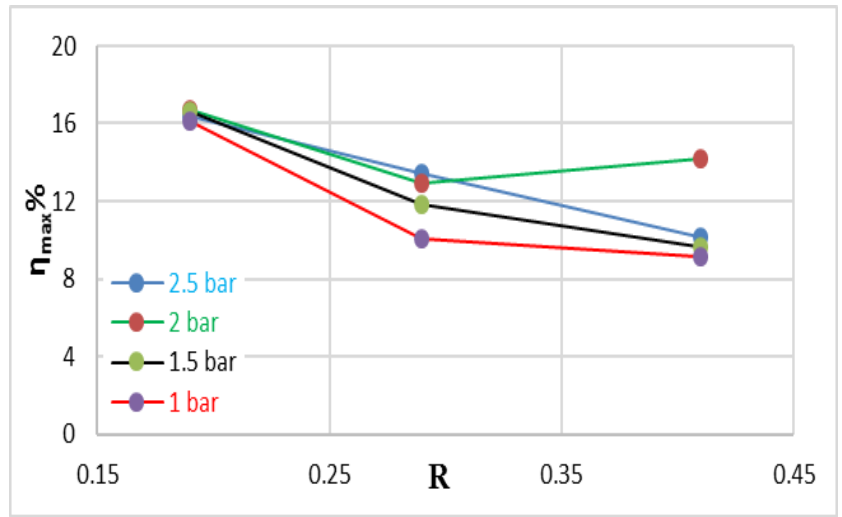

Fig. 4. Maximum efficiency versus area ratio

\section{B. Effect of Area Ratio on the Performance of Jet Pump}

Figures 5 and 6 display the results which illustrate the effect of adjusting the area ratio on the performance of the water jet pump under the conditions of $155 \mathrm{~mm}$ throat length and $5^{\circ}$ diffuser angle. During the study, three different throats with different diameters of 16,13 , and $11 \mathrm{~mm}$ are used in combination with one constant driving nozzle diameter of 7 $\mathrm{mm}$, which delivers three area ratios of $0.19,0.29$, and 0.41 . It is clear from this figure that for the corresponding jet pump arrangement parts and increasing the area ratio, the efficiency and; therefore, the head ratio decreased. The efficiency also increases also with increasing the mass flow ratio. The best values of efficiency and head ratio are for area ratio of 0.19 at $\mathrm{X}($ nozzle to throat spacing to throat diameter ratio $)=1$. 
International Journal of Applied Energy Systems, Vol. 3, No. 2, July 2021
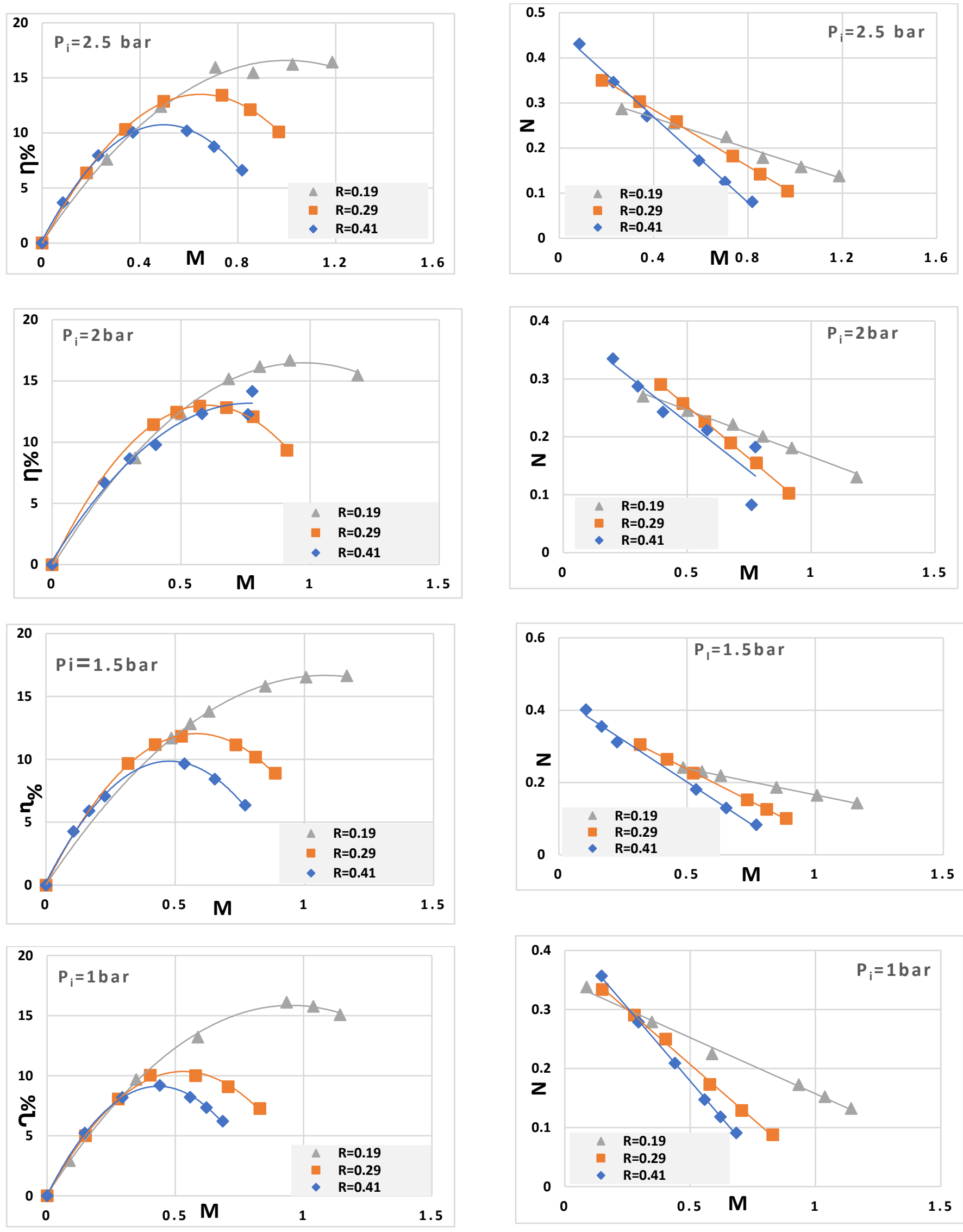

Fig. 5. Jet pump performance $(N-M)$ curves at constant pressure and different area ratios; $R$

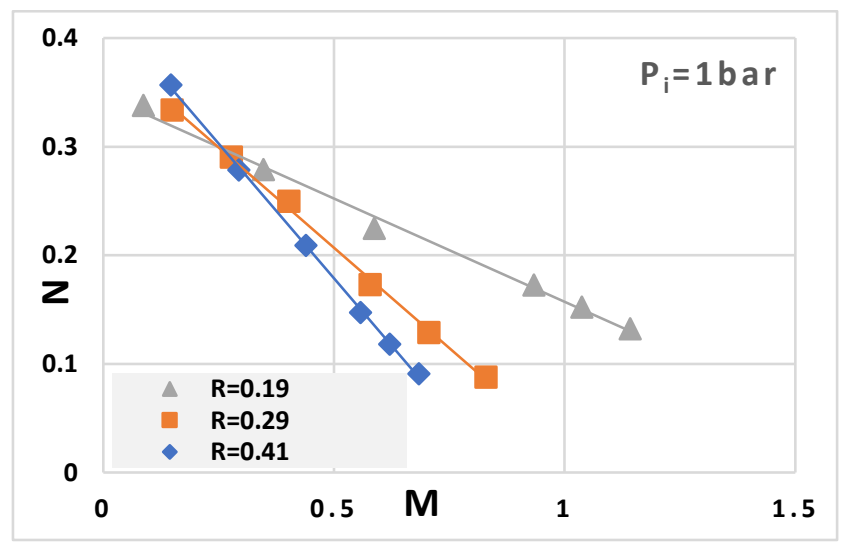

Fig. 6. Jet pump performance $(\eta-M)$ curves at constant pressure and different area ratios; $R$ 


\section{CFD MODELING}

In this section, the numerical arrangement in Fluent is being presented. The simulated pumps are with an area ratio of $R=$ $0.19,0.29$, and 0.41 . A graphic of the $1 / 1$-scale jet pump which is the origin of the simulation study is displayed in figure 7.

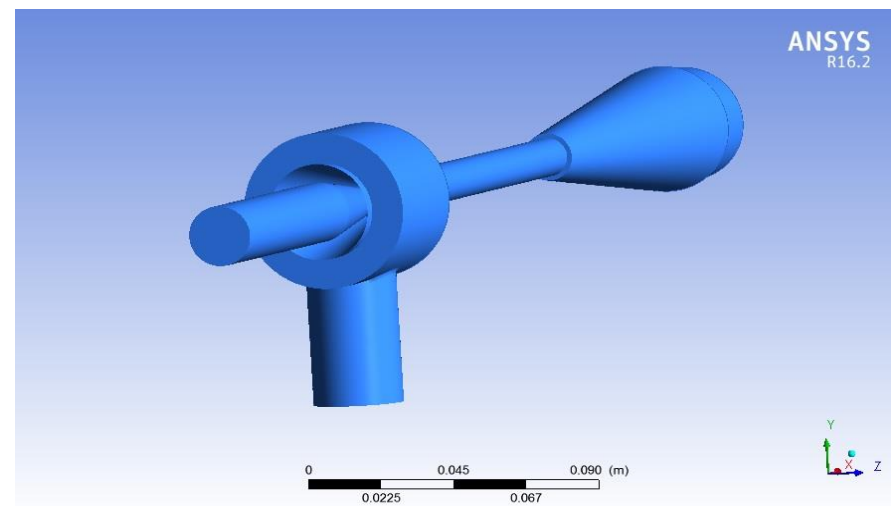

Fig. 7. The geometry of the complete jet pump

\section{A. Mathematical Equations}

The equations required to evaluate an isothermal Newtonian fluid flow are the continuity and momentum balance equations. The mass balance in one volume element gives the continuity equation. Additionally, a turbulence model is required.

$$
\frac{\partial}{\partial x_{j}}\left(\rho u_{j}\right)=0
$$

\section{B. Grid Generation}

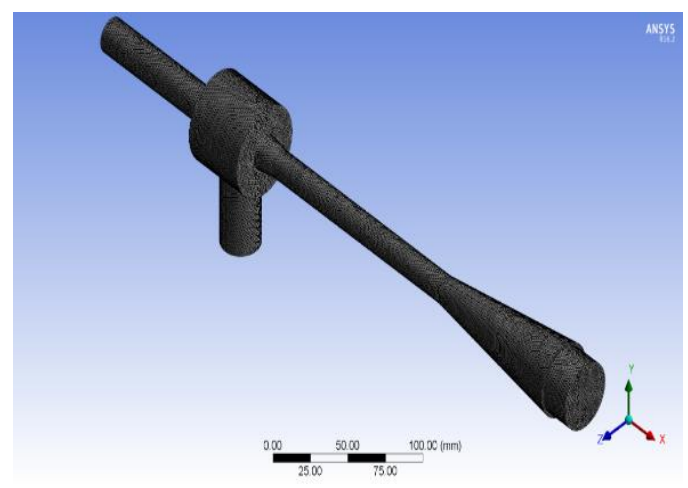

Fig. 8. Jet pump computational grid system

In the CFD study, the jet pump model geometry is identical to the experimental device. Grid was planned to the model geometry using grid-generating software. The grid size is improved to be sufficiently small to ensure that the CFD flows results are virtually independent of size, but large enough to make sure the model ran efficiently at a suitable speed. For optimal meshing, the grid density is improved near the wall and in areas where flow gradients are steep. This is achieved by applying weighting factors to increase the grid density in these areas. Figure 8 shows the grid of the entire domain, suction area, jet nozzle, mixing area, and diffuser area.

\section{Mesh Quality}

Three indicators are used in this study to report the quality of the mesh as shown in the following table.

Table 2 Quality measures for the mesh used in this study

\begin{tabular}{|l|c|c|}
\hline Quality parameter & Limitation & Mesh value \\
\hline Orthogonal quality & $(0-1)$ & 0.86487 \\
\hline Aspect ratio & $(1-100)$ & 1.8176 \\
\hline Skewness & $(0-1)$ & 0.2116 \\
\hline
\end{tabular}

\section{Mesh Independency}

The grid convergence study is performed by developing four different meshes with different number of elements for the geometry of the jet pump. The number of elements simulated for four meshes are summarized in table 3.

Table 3 Mesh details

\begin{tabular}{|l|c|c|c|c|}
\hline No. of mesh & $\mathbf{1}$ & $\mathbf{2}$ & $\mathbf{3}$ & $\mathbf{4}$ \\
\hline No. of Elements & 391309 & 514132 & 718177 & 1406954 \\
\hline No. of nodes & 129627 & 168736 & 232056 & 441212 \\
\hline Suction velocity m/s & 2.010 & 2.031 & 2.028 & 2.041 \\
\hline
\end{tabular}

Figure 9 illustrates the change in fluid exit velocity tested using four meshes. The test results show that there is a convergence between the results in mesh 3 and 4 and hence mesh 3 is taken as they contain less elements to save time and get accurate result

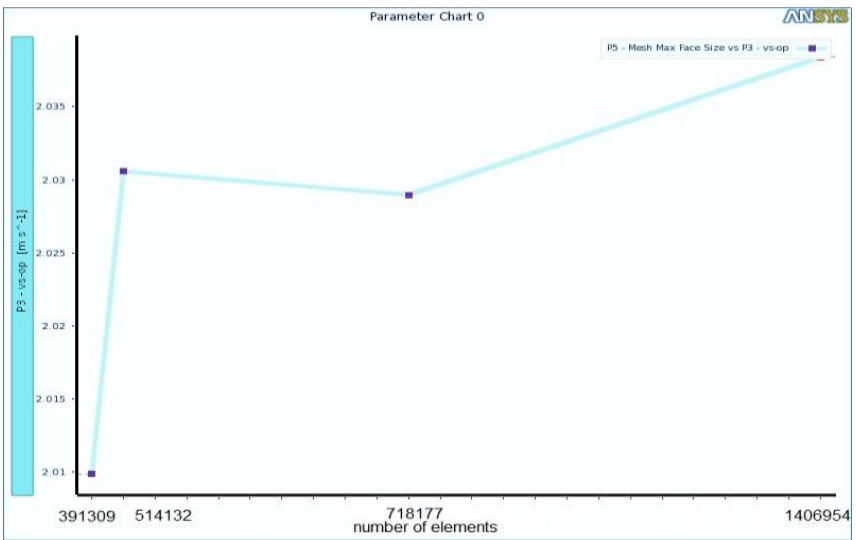

Fig. 9. Mesh independency curve

Table 4 gives a summary of the numerical mesh with 718,177 ; mesh 3 , total number of elements.

Table 4: Summary of the numerical mesh

\begin{tabular}{|c|c|c|c|}
\hline Geometry & Shape & element type & $\begin{array}{c}\text { no of } \\
\text { elements }\end{array}$ \\
\hline Jet pump & 3D & Tetrahedron & 718,177 \\
\hline
\end{tabular}




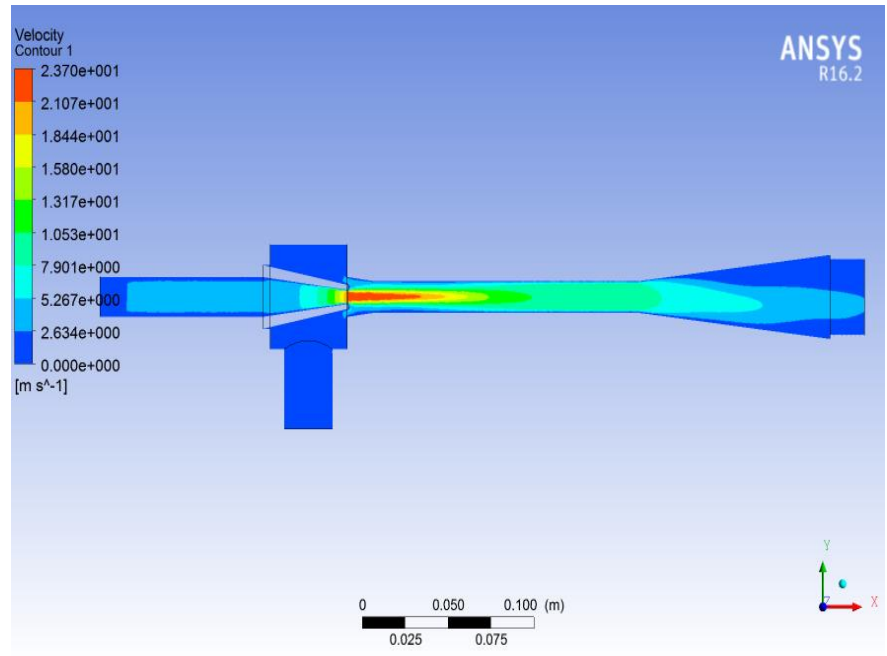

$$
R=0.19
$$

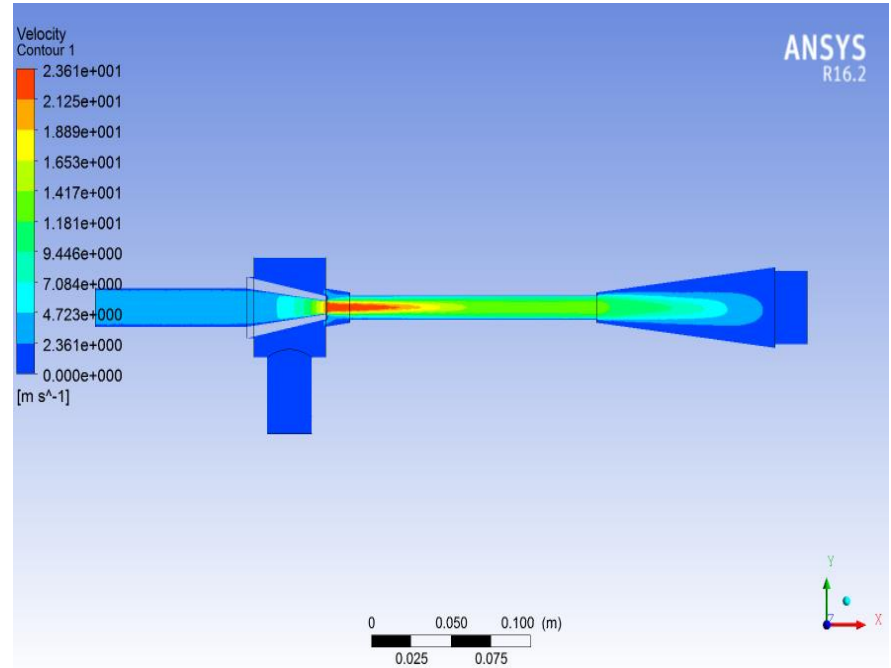

$$
R=0.29
$$

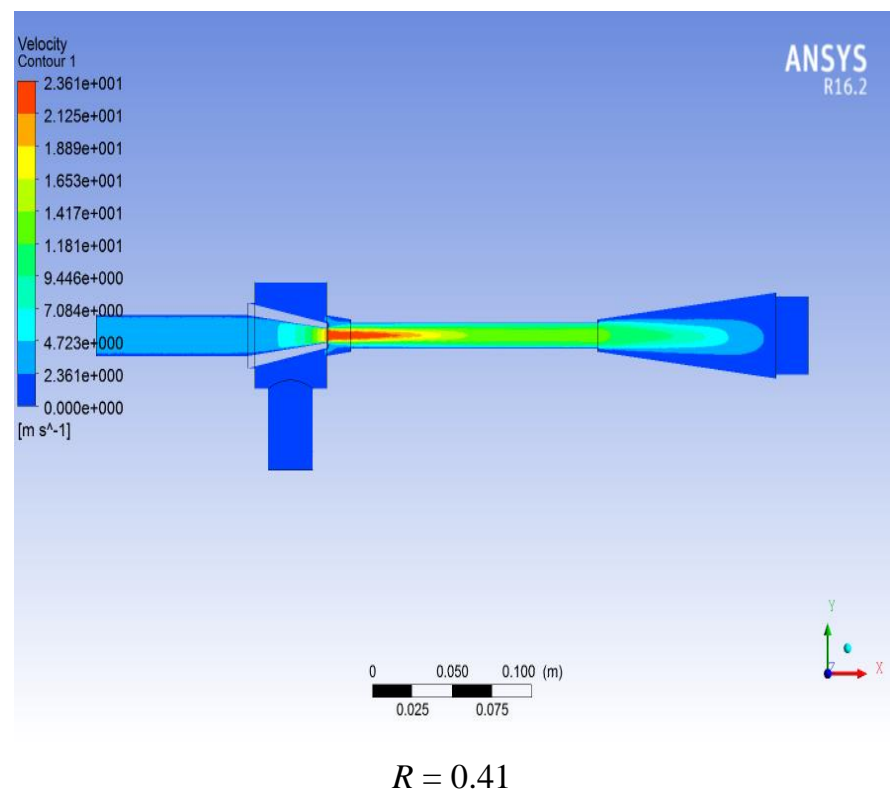

Fig. 10. Pressure contour for suction chamber at different area rati $(R=$ $0.19,0.29$ and 0.41$) d_{n}=7 \mathrm{~mm}, P_{i}=2.5 \mathrm{bar}, X=1, L_{t h}=155$ and $\alpha_{d}=5^{\circ}$
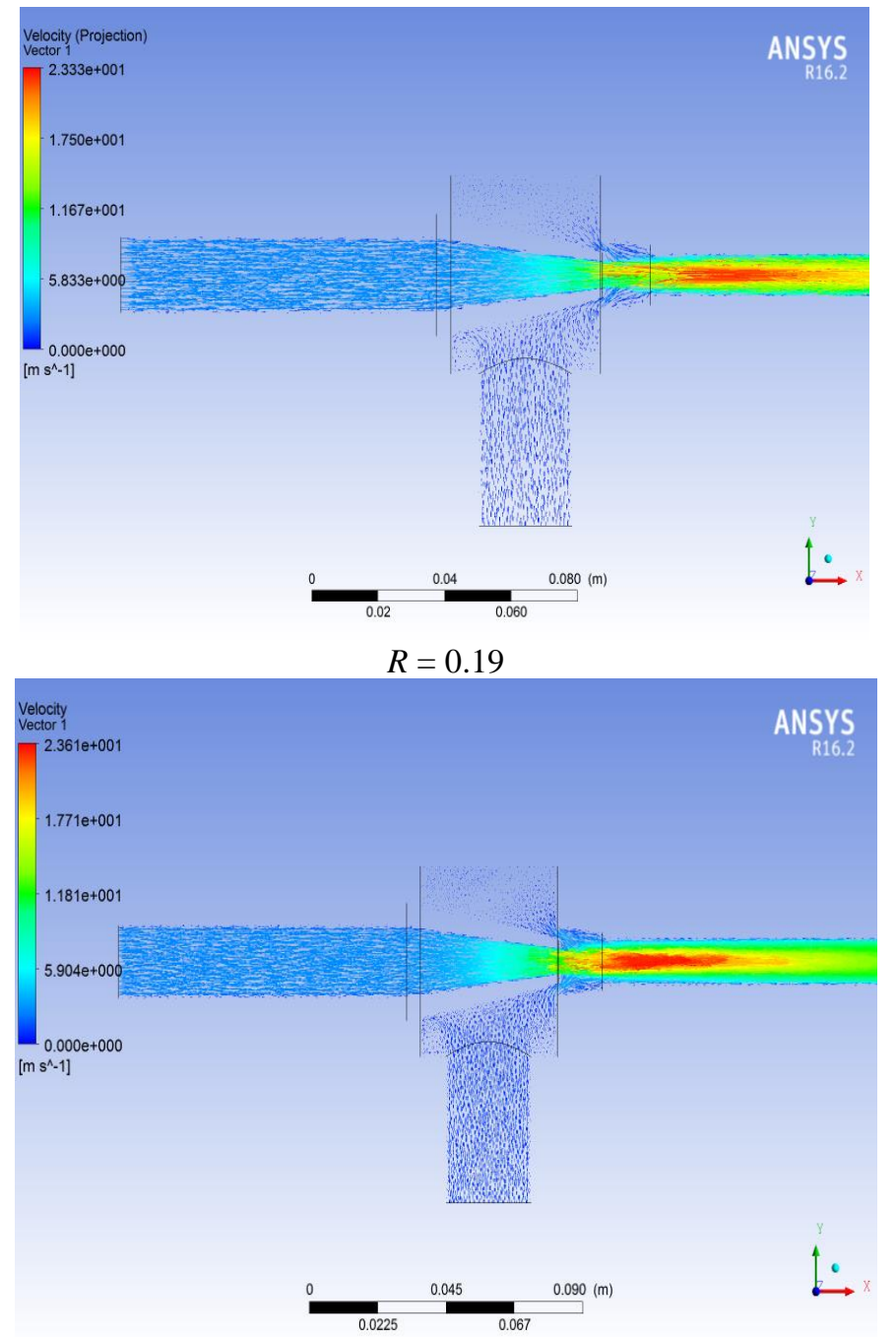

$R=0.29$

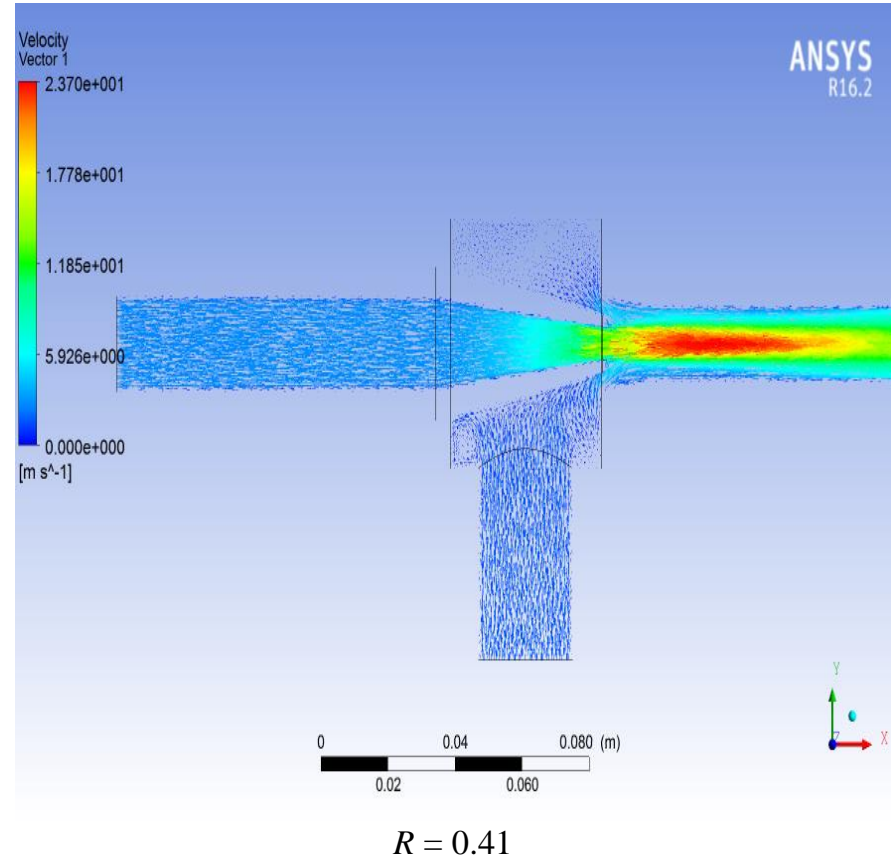

Fig. 11. Velocity vectors for different area ratio $(R=0.19,0.29$ and 0.41$)$ $d_{n}=7 \mathrm{~mm}, P_{i}=2.5$ bar, $X=1, L_{t h}=155$ and $\alpha_{d}=5^{\circ}$ 


\section{E. Boundary Conditions}

To get a correct simulation, the exact dimensions of the tested jet pump are used. As well, the boundary conditions of fluid flow are the same as that of the experimental work. The total pressure of the first and secondary streams giving the proper mass flow ratio at the inlet and therefore, the static outlet pressure is ready as outlet boundary conditions. To succeed in a natural convergence, the number of iterations is 150 for every run.

\section{F. Numerical Results}

In this section, the numerical results reflecting the effect of area ratio; $R$ on the jet pump performance are discussed. CFD simulations allow getting information about the flow inside the pump.

Figure 10 shows the pressure contour in jet pump for the area ratios $R=0.19,0.29$ and 0.41 at motive pressure of 2.5 bar, $X$ $=1$ and $\alpha_{d}=5^{\circ}$. It is clear from the figure that changing the area ratio appreciably affects the pressure distribution along with the jet pump. It may appear that when the area ratio increases, the pressure in the suction line increases.

Figure 11 shows the axial velocity vectors in jet pump for area ratio of $R=0.19,0.29$, and 0.41 at motive pressure of 2.5 bar, $X=1$ and $\alpha_{d}=5^{\circ}$. It is clear from this figure that in the convergent nozzle, the two streams, the high velocity stream jet (primary flow), and the low velocity suction stream (secondary flow), start to mix directly at the exit of the jet nozzle. Then the momentum transfer gradually exists from the high momentum region to the low momentum region. Thus, the velocity of the jet stream decreases as the velocity of the suction stream increases.

\section{COMPARISON BETWEEN NUMERICAL AND EXPERIMENTAL RESULTS OF THE CURRENT INVESTIGATION}

Figures 12 and 13 show a comparison between the experimental and numerical results of $M-N$ and $\eta-M$ curves, for the following specifications: nozzle diameter equals $7 \mathrm{~mm}$ the nozzle to throat spacing to throat diameter; $X=1$, primary pressure of $2.50 \mathrm{bar}$, area ratio; $\mathrm{R}=0.19$, throat length to diameter ratio equals 9.69 and diffuser angle $\alpha_{\mathrm{d}}=5^{\circ}$.

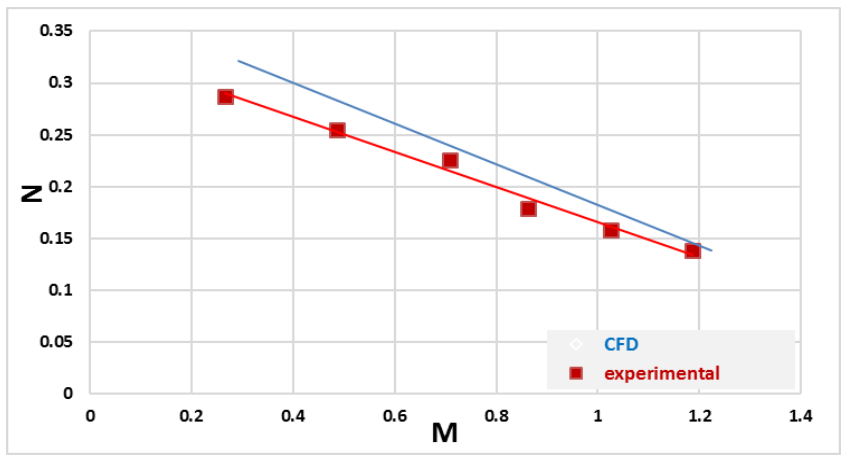

Fig. 12. Comparison of $(M-N)$ curve between the experimental and the numerical results

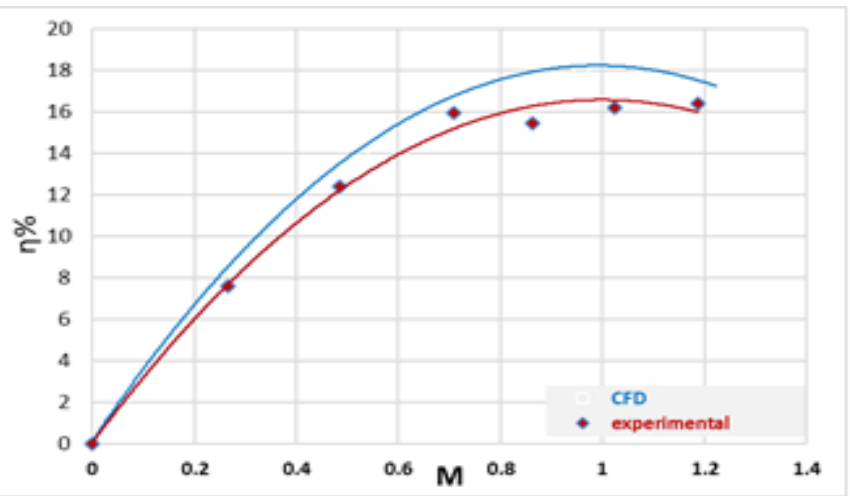

Fig. 13. Comparison of $(M-\eta)$ curve between the experimental and the numerical results

Figures 12 and 13 illustrate comparisons between the experimental and the numerical results, There's a honest agreement between the numerical and experimental results. Figure 13 shows that the theoretical value of efficiency is less than the experimental value by about 3 percent. Furthermore, the figures may show that the numerical results are relatively on the brink of the experimental results.

\section{CONCLUSIONS}

The main aim of the present study is to research the effect of operational and area ratio on the jet pump performance and comparison between the experimental and CFD analyses. The following conclusions are extracted:

- The optimum value of area ratio; which provides the maximum efficiency and head ratio, is $\mathrm{R}=0.19$.

- Increasing the driving pressure increases the flow ratio at maximum efficiency.

- The optimum value for motive fluid pressure is about 2.5 bar

Nomenclature

A Cross sectional area $\left(\mathrm{m}^{2}\right)$

$D \quad$ diameter $(\mathrm{m})$

$g \quad$ Acceleration due to gravity $\left(\mathrm{m} / \mathrm{s}^{2}\right)$

$H$ total head (m)

$K \quad$ friction Loss Coefficients (m)

$L \quad$ Jet pump length (m)

$M \quad$ Flow ratio (-)

$N \quad$ Head ratio (-)

$P \quad$ Pressure (bar)

$Q \quad$ Volume flow rate $\left(\mathrm{m}^{3} / \mathrm{s}\right)$

$R \quad$ Area ratio (-)

$V \quad$ Velocity $(\mathrm{m} / \mathrm{s})$

$X \quad$ The ratio of nozzle-to-throat spacing to throat diameter (-)

$\alpha \quad$ Diffuser angle (deg)

$\varepsilon \quad$ Rate of viscous dissipation $\left(\mathrm{m}^{3} / \mathrm{s}^{3}\right)$

$\chi \quad$ Length of a jet pump from the nozzle $(\mathrm{mm})$

$\eta \quad$ Efficiency (\%)

$\kappa \quad$ Turbulent kinetic energy $\left(\mathrm{m}^{2} / \mathrm{s}^{2}\right)$

Subscripts 
d Discharge

di Diffuser

en Secondary inlet

$i \quad$ Inlet

$n \quad$ Nozzle

$s \quad$ Suction

td Throat-diffuser

th Throat
Pump. Fifteenth International Water Technology Conference, IWTC, 2011.

[22] Aldas K., and Yapici R. Investigation of effects of scale and surface roughness on efficiency of water jet pumps using CFD. Engineering Applications of Computational Fluid Mechanics Vol. 8, No. 1, pp. 14-25 (2014)

[23] Naik B.R. and Patel S.M. The Effect of Venturi Design on Jet Pump Performance. Journal for Research, Volume, 02 Issue, June 2016

\section{References}

[1] Gosline, J., and O'Brien, M., The Water Jet Pump, University of California Publications in Engineering, Vol. 3, No. 3,1934,pp. 167-190.

[2] Cunningham, R. G., and River, w. Jet-pump theory and performance with fluid of high viscosity, Trans. ASME, Vol.79,1957 , PP. 1807-1820.

[3] Vogel, R. Theoretical and experimental investigation of air ejectors. Maschinenbautechnik, Berlin, 5, 1956,pp.619-637.

[4] Mueller, N. H. G., Water Jet Pump, Journal of Hydraulic Division, Vol. 90, No. H.Y 3, pp.83-113, 1964.SATISH P.M., A STUDY OF WATER JET PUMPS. India: University of Baroda. 1963

[5] Reddy, Y. R. and Kar, S., Theory and Performance of Water Jet Pump, Journal of Hydraulic Division, Vol. 94, No. Hy5, pp. 1261-1281, 1968.

[6] Sanger, N. L. "Noncavitating Performance of Two Low-Area - Ratio Water Jet Pumps Having Throat Lengths of 7.25 Diameters", NASA TND-4445, 1968

[7] Grupping, A.W., Coppes, J.L.R., and Groot, J.G., Fundamentals of Oil Well Jet Pumping, SPE Production Engineering, pp.9-14, February 1988.

[8] Hatziavrarnidis, D. T., Modeling and Design of Jet Pumps, SPE .Prod. Engineering, pp.413-419, 1991.

[9] Aissa, W.A., Eissa, M.S., and Mohamed, A.H.H. Experimental and Theoretical Investigation of Water Jet Pump Performance. International Journal of Applied Energy Systems, Vol. 3, No. 1, January 2021.

[10] Karassik I.J., Messina J.P., Cooper P., and Heald C.C. Pump Handbook. New York: McGraw-Hill; 3 edition.

[11] Zandi, I. and Govatos, G., Jet Pump Slurry Transport, Hydrotransport 1, $1^{\text {st }}$ International Conference on the Hydraulic Transport of Solids in Pipes, BHRA, Paper L2, pp. L2-17: L2-32, September, 1970.

[12] El-Sawaf I. A. Halawa M.A., Younes M. A. and Teaima I.R.., Study of The Different Parameters That Influence on The Performance of Water Jet Pump. Fifteenth International Water Technology Conference, IWTC, 2011.

[13] El-Otla, F. M., El-Sawaf, I. A. and El-Ghandour, M. Performance of a Central-Type Jet Pump. (II Experimental Study on Water Flow), 8th International water conference, Alexandria, Egypt, pp.535-551, 2004.

[14] Frank N.L., McDonnel G.A., and Kegel M.F. The Effects of Jet Angle and Geometry on the Performance of the Jet Assisted Air Lift Pump. Fisheries \& Aquatic Sciences Technical Report No. 1062 .November 1981

[15] Gugulothu S.K., Srinivas B.S. and Eshwaraiah P. Experimental Analysis of Single Nozzle Jet Pump with varying Area ratio. Gitam University , Hyderabad, Telangana, India.2014

[16] Saker A.A. and Hassan H.Z. study of the different factors that influence jet pump performance Open Journal of Fluid Dynamics, 2013, 3, 44-49

[17] Kisbocskoi, L., "About the Dimensioning of Water-Jet Pumps", Proceeding of Sixth Conference on Fluid Machinery, Vol.1, Paper 60, pp.567-574, 1979.

[18] Meakhail,T. and Teaima, I., Experimental and numerical studies of the effect of area ratio and driving pressure on the performance of water and slurry jet pumps, J Mechanical Engineering Science 226(9) 2250-2266 IMechE, 2011.

[19] Meakhail,T. and Teaima, I., A Study of the Effect of Nozzle Spacing and Driving Pressure on the Water Jet Pump Performance, International Journal of Engineering Science and Innovative Technology (IJESIT) Volume 2, Issue 5, September 2013

[20] Sheha, A. A., Nasr, M., Wahba, E.M and Hosien, M.A Computational and Experimental Study on the Water-Jet Pump Performance, Journal of Applied Fluid Mechanics, Vol. 11, No. 4, pp. 1013-1020, 2018., 2018.

[21] El-Sawaf I. A. Halawa M.A., Younes M. A. and Teaima I.R.., Study of The Different Parameters That Influence on The Performance of Water Jet 